\title{
Galois’s First Memoir
}

\section{Davide Bondoni}

I appreciated Harold Edwards's contribution [Edw12, pp. 912-923], in which he explains the text of Galois's first memoir step by step. Edwards assumes our knowledge of Galois's theory as the point of departure and uses our modern tools ${ }^{1}$ to clarify his thoughts. I agree with the method of reading the classics from our modern perspective. With good reason, Edwards advises the student to "Study the masters!" The problem is that these masters often worked in a social, cultural, scientific, and temporal setting that is very far from our own.

In this situation what is the best way to study the masters? Certainly, the first step is to edit the sources in the best philological way. ${ }^{2}$ The second step is to modernize the concepts exhibited in the source. By modernize I mean build a bridge between us and the classic text. In the case of Galois, this entails using modern Galois theory, stressing the fact that it was not Galois's creation but rather the result of the work of many mathematicians, each of whom regarded Galois's work from his or her own personal, social, and scientific point of view. Galois theory is a collective work; it is not the genial intuition of Galois alone. As such, it does not make sense to read Galois's memoir assuming it was only his thought.

The myth of Galois thus belongs neither to the "inside" nor to the "outside" of mathematics. It exists, still today, simultaneously in multiple spaces which may be more or less independent from that of mathematical

Davide Bondoni is an Italian independent scholar. His email address is davidebond@yahoo. it.

${ }^{1}$ For example, the concept of splitting field.

${ }^{2}$ Regarding Galois theory, consider the most valuable efforts of Neumann [Neu11], which is a masterwork of precision and inner beauty.

DOI: http://dx.doi.org/10.1090/noti994 research; spaces where it takes on different meanings and serves different agendas. ${ }^{3}$

Using the words of Neumann:

Perhaps the best known myth is that Galois created his theory of groups in the evening and the night before the morning of the duel at the end of May 1832. This myth has its source in the chapter on Galois in [Bel37, pp. 362-377]. ${ }^{4}$

For an example of modernizing, when Edwards substitutes polynomial for Galois's equation, he uses the terminology that is familiar to the 21stcentury reader. Also notice what Edwards states in [Edw12, p. 913]:

...Lemmas 2 and 3 imply a construction of a normal extension of $K$ which is a splitting field of $f(x)$.

The concept of normal extension is not Galois's, but its use lets us appreciate the importance of these two lemmas. In the same way, Edwards introduces the modern concept of automorphism [Edw12, p. 915]. In [Edw12, p. 916, Figure 1] Edwards writes $\Phi(V)$ instead of $\Phi V$ in order to stress that $\Phi$ is a function of $V$. Once more, this is a modern notation.

The point is that reading the masters must develop our knowledge and serve our aims. Using Galois's own vocabulary to explain his thought would be similar to using ancient musical instruments to understand classical compositions. Of course, knowing the possibilities of the instruments lets us comprehend how a score was composed, but whoever plays these instruments is a 21st-century person who cannot ignore his own background. So knowledge of ancient performances could help a modern interpreter, but this person, whether a conductor or a performer, is not a tabula rasa on

\footnotetext{
${ }^{3}$ [Ehr11, p. 199].

${ }^{4}$ [Neu11, p. 383]. Bell is amusing for his romantic taste, but indulges too much on a sort of "reveries".
} 
which the external data collides. He has his own experience, with which he interprets the classics.

It is more or less the same in mathematics. It is impossible to put aside our experience in abstract algebra. What is possible is to use this experience to fill in the gap between our and Galois's time. Trivially, if I write:

$$
(a ; b)_{i j}=\sum_{h} a_{i h} b_{h j},{ }^{5}
$$

does anyone understand? Is it not better to write:

$R \circ S=\{<x, z>\mid \exists y(<x, y>\in R \wedge<y, z>\in S)\} ?$

Galois's case is similar; his writing is not clear. He refused to add particulars and sometimes omitted the proofs. This is one of the reasons that he was never accepted into the Academy. So, on the one hand, we have modern Galois theory as expounded in, for example, Artin [Art98], and on the other hand we have the obscure texts of the master. Personally, it is not easy to recover our modern Galois theory from Galois's own work. For this reason, Edwards's article is an example to imitate. He provides a key to understanding Galois's first memoir from our modern point of view by modernizing it a little. He has composed a sort of introduction to Galois's first memoir, which enables us to appreciate the master's work while carefully taking into account the temporal distance between us, the modern readers, and Galois.

Finally, Edwards makes the difficulty of an idiosyncratic style clear to us. Bell is right on this issue:

Liouville then states that the referees at the Academy had rejected Galois' memoirs on account of their obscurity. He continues: "An exaggerated desire for conciseness was the cause of this defect...Clarity is, indeed, all the more necessary when one essays to lead the reader farther from the beaten path and into wilder territory ...Too often Galois neglected this precept... 6

In the same vein,

Galois' development continued to diverge so widely from the academic course that there was never peace between him and the

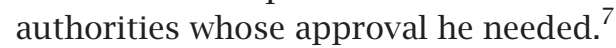

Galois's idiosyncratic way of learning and writing did not conform to the standards of his time, and his being far from any academic institution did not help mathematicians grasp his work.

Finally, Edwards's advice to read the masters is wise, but the reader cannot be left alone with the masters' works. What I have said for Galois I

\footnotetext{
${ }^{5}$ [Sch95, p. 29].

${ }^{6}$ [Bel37, p. 376].

${ }^{7}$ [MM71, p. 98].
}

could say, for example, for Taylor. Who is able to recognize our modern Taylor series at first sight in the corollarium II in [TayXV, p. 23]? Edwards builds a modern bridge that lets us move from our century to Galois's original works. His paper does not present a sharp dichotomy, philology versus modernizing, but rather philology as the servant of our modern comprehension.

\section{Acknowledgments}

I thank dt. Giorgia Boglioli for her precious linguistic revision of a draft of this paper.

\section{References}

[Art98] EMIL ARTIN, Galois Theory, Dover Publications, Inc., Mineola, New York, 1998.

[Bel37] E. T. BELL, Men of Mathematics, Simon \& Schuster Inc., New York-London-Toronto-Sydney, 1937.

[Edw12] HAROLD M. EDWARDS, Galois for 21st-century readers, Notices of the American Mathematical Society 59 (2012), no. 7, 912-923.

[Ehr11] CAROLINE EHRHARDT, Évariste Galois and the social time of mathematics, Revue d'historie des mathématiques 17 (2011), 175-210.

[Jor70] CAMILlE JORDAN, Traité des substitutions et des équations algébriques, Gauthier-Villars, Imprimeur-Libraire, Paris, 1870.

[MM71] JOHN E. MAXFIELD and MARGARET W. MAXFIELD, Abstract Algebra and Solution by Radicals, Dover Publications, Inc., Mineola, New York, 1971.

[Neu11] Peter M. Neumann, The Mathematical Writings of Évariste Galois, European Mathematical Society, Zürich, 2011.

[Sch95] ERNST SCHRÖDER, Vorlesungen über die Algebra der Logik, Teubner Verlag, Leipzig, 1895, dritter Band. Algebra und Logik der Relative.

[Ser54] JOSEPH ALFRED SERRET, Cours d'algébre supérieure, Mallet-Bachelier, Imprimeur-Libraire, Paris, 1854, deuxiéme édition, revue et augmentée.

[TayXV] BROOK TAYLOR, Methodus Incrementorum Directa \& Inversa, Typis Pearsonianis, Londini, 1715. 